\title{
Are there interregional differences in the epidemiology and clinical characteristics of Crohn's disease in the Asia- Pacific region?
}

\author{
Sinwon Lee ${ }^{1}$, Byong Duk Ye \\ ${ }^{1}$ Department of Gastroenterology, ${ }^{2}$ Inflammatory Bowel Disease Center, University of Ulsan College of Medicine, Asan Medical Center, Seoul, Korea
Article: Clinical features of Crohn's disease in Korean patients residing in Busan and Gyeongnam (Intest Res 2016;14:30-36)

The increasing incidence and prevalence of IBD in the Asia-Pacific region demands that more attention be paid to the characteristics of IBD in this part of the world. Differences in the clinical features, prognosis, and genetics of IBD between patients from the Asia-Pacific region and Western patients may call for different management approaches. Therefore, we need to characterize IBD patients in this area more clearly by investigating a substantial number of patients from multiple regions.

The first formal population-based study on the epidemiology of both CD and UC in the Asia-Pacific region was from the Songpa-Kangdong district of Seoul, Korea, which showed increasing incidence rates of both diseases over the 20 years between 1986 and 2005. ${ }^{1}$ Specifically, the mean annual incidence rates of CD increased significantly from 0.05 per 100,000 inhabitants in $1986-1990$ to 1.34 per 100,000 inhabitants in 2001-2005. ${ }^{1}$ For UC, the mean annual incidence rates also increased significantly from 0.34 per 100,000 inhabitants in 1986-1990 to 3.08 per 100,000 inhabitants in 2001-2005. ${ }^{1}$ Later, two Taiwanese studies using the National Health Insurance Research Database also reported progressively increasing incidences of both CD and UC since 1998. ${ }^{2,3}$

Received December 3, 2015. Revised December 4, 2015 Accepted December 4, 2015.

Correspondence to Byong Duk Ye, Department of Gastroenterology and Inflammatory Bowel Disease Center, University of Ulsan College of Medicine Asan Medical Center, 88 Olympic-ro 43-gil, Songpa-gu, Seoul 05505, Korea. Tel: +82-2-3010-3181, Fax: +82-2-476-0824,E-mail: bdye@amc.seoul.kr

Financial support: None. Conflict of interest: None.
A recent population-based study from Wuhan in central China reported the age-adjusted incidences of CD and UC to be 0.51 and 1.45 per 100,000 persons, respectively, in $2010 .{ }^{4}$ According to another population-based study from Zhongshan, Guangdong, China, the age-standardized incidence rates of CD and UC were 1.09 and 2.05 per 100,000 persons, respectively, between 2011 and 2012, which were slightly higher than those found in the Wuhan study. ${ }^{4,5}$ These differences suggest that IBD incidence may vary even between districts within the same country. ${ }^{4,5}$ A recent multinational population-based study conducted across Australia and Asia from 2011 to 2012 showed strikingly different IBD incidences between areas. ${ }^{6}$ The age-standardized annual incidence rates of CD and UC were 14.61 per 100,000 individuals and 7.47 per 100,000 individuals, respectively, in Australia, and $0.05-1.25$ per 100,000 individuals and $0.24-2.05$ per 100,000 individuals, respectively, in Asian countries. ${ }^{6}$

Regarding the clinical characteristics of CD, a Korean study reported male predominance, the peak age at diagnosis of $15-19$ years and a low proportion (12.3\%) of isolated colonic disease. ${ }^{1}$ Male predominance among CD patients has also been observed in Japan, Taiwan, and Zhongshan, but not in Wuhan or Australia. ${ }^{3-7}$ For the Japanese and Zhongshan Chinese population, the peak age at $\mathrm{CD}$ diagnosis was the late teens or early twenties, but in Taiwan and Wuhan, CD was most commonly diagnosed in the mid to late thirties. ${ }^{3-5,7}$ The proportion of isolated colonic CD at diagnosis was only $5.9 \%$ in Zhongshan (even lower than the $12.3 \%$ found in the Korean study), whereas the corresponding figures were $23.5 \%$

๑ Copyright 2016. Korean Association for the Study of Intestinal Diseases. All rights reserved.

This is an Open Access article distributed under the terms of the Creative Commons Attribution Non-Commercial License (http://creativecommons.org/licenses/by-nc/4.0)

which permits unrestricted non-commercial use, distribution, and reproduction in any medium, provided the original work is properly cited. 
and 23.8\% in Wuhan and Australia, respectively. ${ }^{1,4-6}$ Another interesting issue with Asian CD patients is the high frequency of perianal disease. In the population-based study from Zhongshan, the frequency of perianal disease at diagnosis of CD was as high as $58.5 \% .{ }^{5}$ In a Korean hospital-based study that included 2,043 patients, the frequency of perianal fistula was $43.1 \%$ at diagnosis of $\mathrm{CD}^{8}$ However, recent populationbased data from multiple Asian countries showed a frequency of only $17.7 \%$ for perianal disease. ${ }^{6}$ These differences call for more research to be conducted on the frequencies of perianal disease across Asia.

The cumulative probability of intestinal resection 10, 20, and 30 years after diagnosis of CD was $43.5 \%, 70.0 \%$, and $76.1 \%$, respectively, among 2,043 Korean CD patients diagnosed between 1981 and 2012; however, when the researchers divided these patients into three cohorts according to the year of diagnosis of CD, the 2006-2012 diagnosis cohort showed a significantly lower probability of intestinal resection than did the 1981-2000 diagnosis cohort. ${ }^{8}$ This decreasing trend in the intestinal resection rate is consistent with a phenomenon observed in a nationwide cohort study from Denmark. ${ }^{9}$ Put together, the data from multiple Asia-Pacific countries indicate significant differences in the epidemiology and clinical characteristics at diagnosis of IBD between different countries, and even between areas within the same country. However, more studies on IBD epidemiology in various countries of the Asia-Pacific region are needed before definite conclusions can be drawn.

In this issue of Lee et al. present the epidemiological and clinical characteristics of CD patients in defined regions of southeast Korea, the Busan and Gyeongnam provinces. ${ }^{10}$ In a hospital-based multicenter study, they retrospectively enrolled 619 cases of CD diagnosed between 1986 and 2013 and managed in seven tertiary care centers. ${ }^{10}$ They found a continuous increase in the number of $\mathrm{CD}$ patients year by year during the study period (though the incidence rates could not be calculated as this was not a population-based study). ${ }^{10}$ A male predominance, young age at diagnosis (with peak ages around early to mid-twenties), and high frequency of ileocolonic disease were also observed, which were all consistent with previous Korean studies. ${ }^{1,8,10}$ The cumulative probability of intestinal resection $1,5,10$, and 20 years after the diagnosis of CD was $10.3 \%, 14.0 \%, 16.7 \%$, and $36.9 \%$, respectively. ${ }^{10}$ In addition, complicated behavior and absence of perianal fistula at diagnosis of CD were found to be significantly associated with the probability of intestinal resection. ${ }^{10}$ As the authors have admitted, the possibility of a referral bias should be considered because the study was based on data from tertiary care centers, and very severe cases of CD might have been referred to centers outside Busan and Gyeongnam. ${ }^{10}$

Interestingly, the frequency of active and/or past perianal fistula (21.3\%) was lower than that in the previous largescale hospital-based study, which might be because patients with more complicated behaviors were managed at specialized centers outside Busan and Gyeongnam, or because of incomplete history taking on perianal disease. ${ }^{8,10}$ The lower intestinal resection rate than that in the previous study could also be explained by a referral bias. ${ }^{8,10}$ Smoking and early use of thiopurines or biologics could be significantly associated with the probability of intestinal resection; however, these factors were not considered in the multivariate analysis in the present study. ${ }^{10}$ The association between the absence of perianal fistula and the risk of intestinal resection in the present study is not consistent with the general concept of perianal disease as a poor prognostic factor. ${ }^{10}$ This issue also needs to be investigated further in future well-designed studies.

Despite the abovementioned limitations, to our knowledge, this is the first Korean multicenter study on CD epidemiology in a specific province outside Seoul, and it could reflect the characteristics of CD in mixed urban and rural areas in Korea. Long-term population-based epidemiological studies covering rural as well as urban areas could elucidate the clinical features and natural course of IBD in Korea. Similar research in other countries in the Asia-Pacific region would help us understand the characteristics of IBD in this region and the interregional differences.

\section{REFERENCES}

1. Yang SK, Yun S, Kim JH, et al. Epidemiology of inflammatory bowel disease in the Songpa-Kangdong district, Seoul, Korea, 1986-2005: a KASID study. Inflamm Bowel Dis 2008;14:542549.

2. Wei SC, Lin MH, Tung CC, et al. A nationwide population-based study of the inflammatory bowel diseases between 1998 and 2008 in Taiwan. BMC Gastroenterol 2013;13:166.

3. Chuang CH, Lin SH, Chen CY, Sheu BS, Kao AW, Wang JD. Increasing incidence and lifetime risk of inflammatory bowel disease in Taiwan: a nationwide study in a low-endemic area 1998-2010. Inflamm Bowel Dis 2013;19:2815-2819.

4. Zhao J, Ng SC, Lei Y, et al. First prospective, population-based inflammatory bowel disease incidence study in mainland of China: the emergence of "western" disease. Inflamm Bowel Dis 2013;19:1839-1845. 
5. Zeng Z, Zhu Z, Yang Y, et al. Incidence and clinical characteristics of inflammatory bowel disease in a developed region of Guangdong Province, China: a prospective population-based study. J Gastroenterol Hepatol 2013;28:1148-1153.

6. Ng SC, Tang W, Ching JY, et al. Incidence and phenotype of inflammatory bowel disease based on results from the Asiapacific Crohn's and colitis epidemiology study. Gastroenterology 2013;145:158-165.

7. Morita N, Toki S, Hirohashi T, et al. Incidence and prevalence of inflammatory bowel disease in Japan: nationwide epidemiological survey during the year 1991. J Gastroenterol 1995;30(Suppl 8):1-4.
8. Park SH, Yang SK, Park SK, et al. Long-term prognosis of Crohn's disease and its temporal change between 1981 and 2012: a hospital-based cohort study from Korea. Inflamm Bowel Dis 2014;20:488-494.

9. Rungoe C, Langholz E, Andersson M, et al. Changes in medical treatment and surgery rates in inflammatory bowel disease: a nationwide cohort study 1979-2011. Gut 2014;63:1607-1616.

10. Lee EJ, Kim TO, Song GA, et al. Clinical features of Crohn's disease in Korean patients residing in Busan and Gyeongnam. Intest Res 2016;14:30-36. 